\title{
Profitability of a sample of Portuguese bank branches and its decomposition into technical and allocative components
}

\author{
Maria Conceição A. Silva Portela ${ }^{a, b, *}$, Emmanuel Thanassoulis b \\ ${ }^{a}$ Universidade Católica Portuguesa, Centro Regional do Porto, R. Diogo Botelho 1327, 4169-005 Porto, Portugal \\ b Aston Business School, Aston Triangle, B4 7ET Birmingham, UK
}

Keywords: Data envelopment analysis; Profit efficiency; Bank branches

\begin{abstract}
The efficiency literature, both using parametric and non-parametric methods, has been focusing mainly on cost efficiency analysis rather than on profit efficiency. In for-profit organisations, however, the measurement of profit efficiency and its decomposition into technical and allocative efficiency is particularly relevant. In this paper a newly developed method is used to measure profit efficiency and to identify the sources of any shortfall in profitability (technical and/or allocative inefficiency). The method is applied to a set of Portuguese bank branches first assuming long run and then a short run profit maximisation objective. In the long run most of the scope for profit improvement of bank branches is by becoming more allocatively efficient. In the short run most of profit gain can be realised through higher technical efficiency.
\end{abstract}

\section{Introduction}

The measurement of profit efficiency and its decomposition into technical and allocative components has been performed, in the context of non-parametric methods (best known as data envelopment analysis (DEA)), through two different approaches. One of the approaches uses ratios of profit to measure various types of efficiency (see e.g. Berger and Mester, 2000; Banker and Maindiratta, 1988), and the other calculates efficiency based on the adjustments required to move both inputs and outputs ${ }^{1}$ to the technical efficient frontier, or to the maximum profit frontier. The latter approach may use alternative models (hyperbolic

\footnotetext{
${ }^{*}$ Corresponding author. Tel.: +351-22-6196200; fax: +351-22-6196291.

E-mail addresses: csilva@porto.ucp.pt, portemca@aston.ac.uk (M.C.A. Silva Portela), e.thanassoulis@aston.ac.uk (E. Thanassoulis).

${ }^{1}$ Note that in a profit setting both inputs and outputs are assumed controllable. If this was not the case then profit maximisation would reduce to cost minimisation if only inputs were controllable, or to revenue maximisation if only outputs were controllable.
} 
model of Färe et al. (1985), directional model of Chambers et al. (1996, 1998), or the model of Chavas and Cox (1999)) to measure profit efficiency and decompose it into its technical and allocative components. As shown in Portela and Thanassoulis (2002) both the ratio and adjustment approaches are equivalent in a cost minimisation or revenue maximisation setting, but not in a profit maximisation setting because simultaneous changes in inputs and outputs cannot be readily reflected in profit ratios. This fact introduces some problems for the measurement of profit efficiency, the first of which relates to the choice of approach (ratio or input/ output adjustment) to use since they are not equivalent. In addition, the ratio approach may result in negative efficiency measures when observed profit is negative. The adjustments approach, on the other hand, may result in profit maximising targets that lie on the maximum profit frontier but outside the production possibilities set (such projections do no have an easy economic interpretation). Furthermore, measures of profit and technical efficiency based on existing approaches can leave parts of inefficiency unaccounted for (for details see Portela and Thanassoulis, 2002).

The measurement and decomposition of profit efficiency is done in this paper through a newly developed approach, that overcomes the problems mentioned above. Our approach is called geometric distance function (GDF) and is fully detailed in Portela and Thanassoulis (2002). The GDF approach measures and decomposes profit efficiency based on input/output adjustments, but recognises that the computation of profit ratios (or differences) can be useful in complementing the analysis. 'Adjustments' are understood in the GDF framework as distances between observed points and technical efficient or maximum profit points. The GDF measure has the advantage of being capable of incorporating all the sources of inefficiency, and of being decomposable into technical and allocative efficiency. Allocative efficiency is further decomposed in this paper into a scale effect and a pure mix effect.

The GDF approach is applied in this paper to a set of Portuguese bank branches. As for-profit organisations bank branches are necessarily concerned with increasing profits, and therefore with measuring profit efficiency, i.e. the extent to which production plans are profit maximising. These concerns have been acknowledged in some previous bank branch studies either through the use of the intermediation approach (which by considering cost sources on the input side and revenue sources on the output side is closely linked with the profit concept), or through post hoc analysis where operational efficiency is compared with profitability. The former approach has been followed, for example, by Athanassopoulos (1997), Oral and Yolalan (1990), and Berger et al. (1997). The latter approach was followed by Schaffnit et al. (1997) and by Camanho and Dyson (1999).

Our analysis differs from those in the literature by considering price information explicitly, and by using a profit maximisation model, which was not, to the authors' knowledge, used before in analysing bank branches efficiency. In fact, when price information is available cost analyses are more common than profit analyses.

In the context of measuring the efficiency of bank branches cost and/or allocative efficiency analyses were performed by Schaffnit et al. (1997) and Hartman et al. (2001) ${ }^{2}$ as far as the application of DEA is concerned, and by Pavlopoulos and Kouzelis (1989), Doukas and Switzer (1991), Berger et al. (1997) as far as the application of parametric techniques is concerned. Berger et al. (1993) used profit functions to analyse banks' efficiency, recognising that a cost analysis shows only part of a wider picture as higher costs are not necessarily associated with lower efficiency (higher quality, for example, is likely to be produced at the expense of higher costs but it is also likely to generate more revenues). Only the parametric bank efficiency literature has adopted this perspective, as the rising number of profit efficiency studies demonstrates (some examples are Siems and Clark, 1997; Lozano Vivas, 1997; Humphrey and Pulley, 1997). As far as the non-parametric and bank branches literature is concerned a profit analysis has not, to the authors' knowledge, been published before.

\footnotetext{
${ }^{2}$ This was however done differently as Schaffnit et al. (1997) used assurance regions containing information on prices to derive allocative efficiency.
} 
A final remark concerns the fact that the profit efficiency analysis presented in this paper is part of a wider study where other dimensions of performance are considered. Operational efficiency is also being measured (the extent to which a bank branch increases its customers' base, improves its sales, and performs basic transactions, given its environment and level of staff), while at the same time efficiency measures (operational and profit) are being compared with service quality, an increasingly important dimension in service organisations like banks.

In the next section the main steps required to decompose profit efficiency according to the GDF approach are put forward. Some extensions to the original approach are developed here to accommodate some specificities of the data set. In Section 3 the methodology is applied to the data, and Section 4 analyses short run profit maximisation by introducing additional constraints in the profit model. Section 5 concludes the paper.

\section{The GDF and its use for profit effciency measurement}

The GDF is defined in (1), where $\theta_{i}$ represents the ratio between a target input and an observed input $i$ $\left(x_{i}^{*} / x_{i}\right)$ and $\beta_{r}$ represents the ratio between a target output and an observed output $r\left(y_{r}^{*} / y_{r}\right)$.

$$
(\mathrm{GDF})=\frac{\left(\Pi_{i} \theta_{i}\right)^{1 / m}}{\left(\Pi_{r} \beta_{r}\right)^{1 / s}} .
$$

Depending on the target points considered in (1), the final GDF may be measuring profit efficiency (if targets are maximum profit), technical efficiency (if targets are technically efficient), and allocative efficiency (if targets are maximum profit and observed points are replaced by technical efficient points). Note that under specific circumstances the GDF efficiency measure reduces to well known efficiency measures in the DEA literature. For example, when target points are computed radially the GDF reduces to $\theta$ if input orientation is used, or to $1 / \beta$ if output orientation is used, corresponding to the well known Farrell input and output efficiency measures, respectively.

The use of the GDF for profit efficiency measurement requires (according to Portela and Thanassoulis (2002)) a multi-stage procedure, that is summarised below.

1. Calculate maximum profit targets and use GDF in (1) to calculate overall profit efficiency;

2. Calculate technically efficient targets and use GDF in (1) to calculate technical profit efficiency;

3. Calculate allocative profit efficiency either by decomposition, or using the GDF in (1) where the two points to consider are the maximum profit target and the technical efficient target;

4. Decompose allocative profit efficiency into scale and mix effects.

Each of these steps will be shortly detailed next.

Calculate maximum profit targets and overall profit efficiency

The model used to calculate maximum profit is presented in (2) (see e.g. Färe et al., 1990, 1994), where input and output quantities $\left(x_{i}, y_{r}\right)$ are the choice (endogenous) variables, and output and input price vectors (p and $\mathbf{w}$ ) are assumed exogenously fixed ${ }^{3}$ for each unit $o$ being assessed.

\footnotetext{
${ }^{3}$ The assumption of exogenously fixed prices is usually an assumption of perfectly competitive markets. We do not maintain the assumption of perfectly competitive markets, but the exogeneity of prices was required since bank branches do not have full discretion on factor prices which are set centrally (see e.g Cherchye et al. (2001), that allow for endogenous price information).
} 


$$
\begin{aligned}
\max _{\lambda_{j}, y_{r}, x_{i}}\{ & \sum_{r=1}^{s} p_{r o} y_{r}-\sum_{i=1}^{m} w_{i o} x_{i} \mid \sum_{j=1}^{n} \lambda_{j} y_{r j}-y_{r} \geqslant 0, r=1, \ldots, s, \\
& \left.\sum_{j=1}^{n} \lambda_{j} x_{i j} .-x_{i} \leqslant 0, i=1, \ldots, m, \sum_{j=1}^{n} \lambda_{j}=1, \lambda_{j} \geqslant 0, j=1, \ldots, n\right\} .
\end{aligned}
$$

Model (2) assumes a variable returns to scale (VRS) technology as it could not yield a finite solution if the technology exhibited globally increasing returns to scale (IRS) (profit would be maximised at infinity) or constant returns to scale (CRS) (profit may also be maximised at infinity or the profit hyperplane may intersect the efficient frontier at the origin (maximum profit is zero)). There are two important implications of assuming VRS in model (2): (i) We do not assume perfectly competitive markets since under this assumption all firms have zero profits in the long run, while in (2) maximum profit may be positive; (ii) Maximum profit units do not need to be most productive scale size (mpss) units in the sense of Banker (1984). That is, maximum profit units do not need to be scale efficient (see also Kuosmanen, 1999).

The level of outputs $y_{r}$ and the level of inputs $x_{i}$ that maximise profit in (2) are the targets used in (1) to calculate overall profit efficiency. The overall profit efficiency compares, therefore, the observed point with the maximum profit target and it can take any positive value (see for details Portela and Thanassoulis, 2002). A value of 1 is a necessary but not sufficient condition for the assessed unit to be maximum profit. A GDF overall profit efficiency equal to 1 indicates that the geometric average change in inputs equals the geometric average change in outputs, which might happen when the two points being compared are the same or not. Therefore, the necessary and sufficient condition for overall profit efficiency is that the maximum profit point is coincident with the observed point in which case the overall profit efficiency measured by GDF will be 1. Because of the averaging process within the computation of the overall profit efficiency through the GDF it is necessary to further decompose it, so that one can better understand and interpret its value.

Calculate technically efficient targets and technical profit efficiency

The computation of technical efficient targets can be done through any model that leads to a Paretoefficient point as long as it is non-oriented. ${ }^{4}$ However, in order to identify targets that are easier for the unit being assessed to achieve we propose a procedure that finds closest targets (CTs) (for details see Portela et al., 2003). The reasons for selecting CTs relate with these being more practicable for the units to attain and more in line with the way management exercise judgment in general. In addition, most of the non-oriented technical efficiency models in the literature tend to maximise the distance from the observed point to the technically efficient target point (for details see Portela et al., 2003), meaning that production units are not shown in their best possible light.

The CT procedure of Portela et al. (2003) requires the identification of facet members, which are determined through the use of QHull. ${ }^{5}$ In a second step, model (3) is solved for each inefficient unit in relation to each Pareto-efficient facet $\left(F_{k}\right)$ (see Olesen and Petersen, 1996, 2002; on the use of QHull for finding efficient facets in a DEA model).

$$
\min _{\lambda_{j}, \beta_{i o} \gamma_{r o}}\left\{\sum_{r=1}^{s} \gamma_{r o}+\sum_{i=1}^{m} \beta_{i o} \mid \sum_{j \in F_{k}} \lambda_{j} y_{r j}=y_{r o}+\gamma_{r o} y_{r o}, \sum_{j \in F_{k}} \lambda_{j} x_{i j}=x_{i o}-\beta_{i o} x_{i o}, \sum_{j \in F_{k}}^{n} \lambda_{j}=1, \lambda_{j}, \gamma_{r o}, \beta_{i o} \geqslant 0\right\} .
$$

\footnotetext{
${ }^{4}$ In a profit setting only non-oriented technical efficiency models make sense because oriented models assume that all inputs or all outputs are non-controllable. In economic terms this means that costs or revenues are fixed and therefore a profit analysis reduces to a revenue maximisation or to a cost minimisation analysis.

${ }^{5}$ QHull is a freely available software-www.geom.umn.edu/software/qhull.
} 
Model (3) yields Pareto-efficient targets whose distance to the observed point (measured by the sum of normalised slacks: $\sum_{r=1}^{s} \gamma_{r o}+\sum_{i=1}^{m} \beta_{i o}$ ) is minimum. Technical profit efficiency is then measured as the GDF distance between the observed point and the technical efficient point that is its CT. Calculated in this way the technical profit efficiency component ranges between 0 and 1 . A value of 1 means the observed point is Pareto-efficient, while a value below 1 means the observed point is not Paretoefficient.

Note that in moving from the observed to the technical efficient target (as given by model (3)) the mix within inputs or within outputs is not necessarily preserved, but eventual changes in mix in such a movement are not sought to in any way reflect factor prices.

Calculate allocative profit efficiency

Since overall profit efficiency $=$ technical profit efficiency $\times$ allocative profit efficiency, allocative profit efficiency can be obtained dividing the overall profit efficiency by the technical profit efficiency. Alternatively, allocative profit efficiency may be calculated applying the GDF between the technical efficient point as resulting from stage 2 and the maximum profit point obtained in stage 1 .

The allocative profit efficiency reflects movements from a technically efficient point $\left(\mathbf{x}^{\prime}, \mathbf{y}^{\prime}\right)$ to a maximum profit point $\left(\mathbf{x}^{*}, \mathbf{y}^{*}\right)$. Such movements imply changes in the mix of inputs and/or outputs that are dictated by factor prices. However, movements from a technical efficient point to a maximum profit point may not only imply changes in mix but also changes in scale size. Note, for example, that in the single input/output case all allocative profit inefficiency is in fact scale inefficiency (Lovell and Sickles, 1983).

The interpretation of allocative efficiency values will be undertaken next, when we show how allocative efficiency can be decomposed into mix and scale effects and interpret each of these components.

Decompose allocative profit efficiency

Following Portela and Thanassoulis (2002) we isolate the scale and the mix components of the allocative profit efficiency through model (4).

$$
\min _{\alpha, \gamma, s_{r}, e_{i}}\left\{\alpha / \gamma \mid y_{r}^{*}-s_{r}=\gamma y_{r}^{\prime}, r=1, \ldots, s, x_{i}^{*}+e_{i}=\alpha x_{i}^{\prime}, i=1, \ldots, m, s_{r}, e_{i} \geqslant 0\right\} .
$$

In constructing model (4) we assume that scale effects resulting of movements from the technically efficient point $\left(\mathbf{x}^{\prime}, \mathbf{y}^{\prime}\right)$ to the maximum profit point $\left(\mathbf{x}^{*}, \mathbf{y}^{*}\right)$ (which is also technically efficient) exist when we can increase (decrease) all inputs proportionally and all outputs proportionally without going 'above' the maximum profit point (and therefore: $y_{r}^{*} \geqslant \gamma y_{r}^{\prime}$ and $x_{i}^{*} \leqslant \alpha x_{i}^{\prime}$ ). This means that the scale adjusted point $\left(\alpha \mathbf{x}_{i}^{\prime}, \gamma \mathbf{y}_{r}^{\prime}\right)$ will lie on the free disposable hull of the maximum profit point, since at least one input and one output will be equal to that of the maximum profit point with the remaining inputs being no lower and the remaining outputs being no higher.

Model (4) provides 'radial' (measured through $\alpha$ and $\gamma$ ) and 'non-radial' adjustments (measured through the $s_{r}$ and $e_{i}$ ) required to move from a technical efficient to a maximum profit point. The radial adjustments reflect scale effects (given directly by $\alpha / \gamma$ ), while the non-radial adjustments reflect changes in the mix of inputs and outputs. Note that in order for scale effects to exist one needs to have both $\alpha$ and $\gamma \geqslant 1$ or both $\alpha$ and $\gamma \leqslant 1$. In fact having simultaneously a value of $\gamma>1$ and $\alpha<1$ implies a movement from the technically efficient point to a point outside the production possibilities set, which is not a viable movement since the scale adjusted point would not lie on the free disposal hull of the maximum profit point. Having simultaneously a value of $\gamma<1$ and $\alpha>1$ results in a movement towards technical inefficiency, that reduces profit rather than increasing it, which is not coherent with the profit maximisation objective. Therefore. if it is not possible to find in (4) values of $\alpha$ and $\gamma$ that point to movements in the same direction, then one would conclude for the non-existence of scale effects in moving from a technical efficient point to a maximum profit point and therefore all allocative efficiency would be due to mix changes. 
When scale effects can be identified through model (4), if $\alpha / \gamma$ is higher than 1 then it means that in moving from the technical efficient point to the maximum profit point the assessed unit would experience an average increase in inputs that is more than proportional to the average increase in outputs. Thus decreasing returns to scale (DRS) are implicit in this movement. If the value is lower than 1, then IRS are implicit in the movement.

When scale effects do exist, the pure mix effect of the allocative profit efficiency can be calculated through the GDF where the points considered are the scale adjusted point and the maximum profit point. As from model (4) $y_{r}^{*} \geqslant \gamma y_{r}^{\prime}$ and $x_{i}^{*} \leqslant \alpha x_{i}^{\prime}$, then the maximum profit point has higher outputs and lower inputs than the scale adjusted point meaning that the mix effect (reflecting the GDF distance between these two points) cannot be higher than 1 . Therefore, for the situation where scale effects do exist an allocative profit efficiency, which is the product of scale and mix effects, when greater than 1 would be the result of a scale effect greater than 1 . Such a scale effect is not favourable for the production unit from the pure technological perspective, but may be so from a profit perspective.

When scale effects cannot be identified from model (4), all allocative efficiency is due in this case to changes

in the mix of inputs and outputs. Therefore, an allocative efficiency measure $\left(\left(\Pi_{i} \frac{x_{i}^{*}}{x_{i}^{\prime}}\right)^{1 / m} /\left(\Pi_{r} \frac{y_{r}^{*} y_{r}^{*}}{y^{1 / s}}\right)\right.$ greater than 1 means that the geometric average change in inputs is higher than the geometric average change in outputs in moving from the technical efficient point to the maximum profit point. This means that this movement in fact implies a decrease in the physical productivity of the unit being assessed as will become clear in the next section. Such movements may not be advisable from a pure technological perspective, though they are so from a profit perspective. Values of the allocative efficiency lower than 1 mean that the geometric average change in inputs is lower than the geometric average change in outputs and therefore such movements are advisable both from a profit and from a technological perspective.

\section{Unknown prices and profit effciency measurement}

The above procedure for calculating and decomposing profit efficiency is applied in the present paper to a sample of Portuguese bank branches. The data at hand requires, however, a development on the above procedure that relates to finding maximum profit when some factor prices are unknown.

Model (2) assumes that prices are known for each factor included in the computation of maximum profit. In practice, however, some prices may be unknown. In this situation, a commonly used assumption is that prices are equal for all production units (see e.g. Färe et al., 1990). Being this so, the calculation of maximum profit can be equivalently undertaken through the use of price and quantity information (when prices are known), or cost and revenue information (when prices are unknown).

Under the assumption of equal prices for all units the maximum profit model (2) turns out to be equivalent to model (5), where $R_{r}=p_{r} y_{r}, C_{i}=w_{i} x_{i}, R_{r j}=p_{r} y_{r j}$, and $C_{i j}=w_{i} x_{i j}$ (see Färe et al., 1990; who proved this equivalence).

$$
\max _{\lambda_{j}, R_{r}, C_{i}}\left\{\sum_{r=1}^{s} R_{r}-\sum_{i=1}^{m} C_{i} \mid \sum_{j=1}^{n} \lambda_{j} R_{r j} \geqslant R_{r}, r=1, \ldots, s, \sum_{j=1}^{n} \lambda_{j} C_{i j} \leqslant C_{i}, i=1, \ldots, m, \sum_{j=1}^{n} \lambda_{j}=1\right\} .
$$

As stated in (5) the model needs to be solved only once, and maximum profit is equal for all DMUs.

Model (5) corresponds to the extreme case where no prices are known for any factor. It may however be the case that prices are known for some factors and unknown for others. In this situation we can think of a mixed profit maximisation model of the type shown in (6), where unknown prices are assumed to be equal for all production units. 


$$
\begin{aligned}
\max _{\lambda_{j}, y_{r}, x_{i}, R_{r}, C_{i}} & \left\{\sum_{r=1}^{k} p_{r o} y_{r}-\sum_{i=1}^{l} w_{i o} x_{i}+\sum_{r=k+1}^{s} R_{r}-\sum_{i=l+1}^{m} C_{i} \mid \sum_{j=1}^{n} \lambda_{j} y_{r j} \geqslant y_{r}, r=1, \ldots, k\right. \\
& \sum_{j=1}^{n} \lambda_{j} x_{i j} . \leqslant x_{i}, i=1, \ldots, l, \sum_{j=1}^{n} \lambda_{j} R_{r j} \geqslant R_{r}, r=k+1, \ldots, s \\
& \left.\sum_{j=1}^{n} \lambda_{j} C_{i j} \leqslant C_{i}, i=l+1, \ldots, m, \sum_{j=1}^{n} \lambda_{j}=1\right\} .
\end{aligned}
$$

Considering $R_{r}=p_{r} y_{r}$ and $C i=w_{i} x_{i}$, where $p_{r}$ and $w_{i}$ are assumed equal across all units the equivalence between this model and the maximum profit model (2) can be easily proved (we omit the proof here for sake of brevity).

Maximum profit targets are useful for calculating overall profit efficiency, which is usually disentangled into its technical and allocative components. The use of a 'mixed' maximum profit model does not pose a problem for this task as the variables to be used in the technical and allocative models are also the quantities of inputs and outputs for which prices are known and the costs and revenues associated with inputs and outputs for which prices are unknown. In our case the technical efficiency model in (3) is modified to (7).

$$
\begin{aligned}
\min _{\lambda_{j}, \gamma_{r o}, \beta_{i o}}\{ & \sum_{r=1}^{s} \gamma_{r o}+\sum_{i=1}^{m} \beta_{i o} \mid \sum_{j \in F_{k}} \lambda_{j} y_{r j}=y_{r o}+\gamma_{r o} y_{r o}, r=1, \ldots, k, \\
& \sum_{j \in F_{k}} \lambda_{j} x_{i j}=x_{i o}-\beta_{i o} x_{i o}, i=1, \ldots, l, \sum_{j \in F_{k}} \lambda_{j} R_{r j}=R_{r o}+\gamma_{r o} R_{r o}, r=k+1, \ldots, s, \\
& \left.\sum_{j \in F_{k}} \lambda_{j} C_{i j}=C_{i o}-\beta_{i o} C_{i o}, i=l+1, \ldots, m, \sum_{j \in F_{k}} \lambda_{j}=1, \lambda_{j}, \gamma_{r o}, \beta_{i o} \geqslant 0\right\} .
\end{aligned}
$$

Assuming equal prices we have that $\sum_{j \in F_{k}} \lambda_{j} R_{r j}=R_{r o}+\gamma_{r o} R_{r o} \Longleftrightarrow \sum_{j \in F_{k}} \lambda_{j}\left(p_{r} y_{r j}\right)=\left(p_{r} y_{r o}\right)+$ $\gamma_{r o}\left(p_{r} y_{r o}\right) \Longleftrightarrow p_{r} \sum_{j \in F_{k}} \lambda_{j} y_{r j}=p_{r}\left(y_{r o}+\gamma_{r o} y_{r o}\right) \Longleftrightarrow \sum_{j \in F_{k}} \lambda_{j} y_{r j}=y_{r o}+\gamma_{r o} y_{r o}$, which proves the equivalence between constraints using revenues and constraints using quantities of outputs, when prices are assumed equal across production units. For the input case the proof is analogous.

\section{Application to bank branches}

The measurement and decomposition of profit efficiency follows the approach outlined in Section 2, and uses the input and output variables listed in Table 1.

These variables are consistent with the intermediation approach of bank branches' activities as discussed in Athanassopoulos (1997) and Berger et al. (1997).

Apart from the 'quantity' variables specified in Table 1, price data were also available for staff (average salaries) and for all the outputs. We used the variables in Table 1 to compute two types of efficiency:

Table 1

Inputs and outputs to assess profit efficiency

\begin{tabular}{ll}
\hline Inputs & Outputs \\
\hline Number of staff [staff] & Value current accounts [curracc] \\
Supply costs [supplycost] & Value other resources [othress] \\
& Value credit by bank [credb] \\
& Value credit associates [credass] \\
\hline
\end{tabular}


technical and overall profit efficiency. For the technical profit efficiency measurement we used the variables as specified in Table 1. For calculating overall profit efficiency we used the 'quantity' data specified in Table 1 plus price information for all the variables in this table, except for supply costs (see Section 2.1).

The chosen inputs are intended to capture two major sources of costs to bank branches (staff and supply costs). Apart from these inputs, interest costs could also have been considered since they are an important source of costs to bank branches. However, the bank could not supply interest costs directly but only indirectly through the prices of the outputs. Indeed, output prices are net interest rates that account for the active and passive interest rates. In this sense the product of output prices and output quantities results in net interest revenue, i.e. interest revenue minus interest cost.

The outputs specified in Table 1 are intended to capture the major sources of revenue to the bank branch. This revenue is obtained by multiplying the value of the various items considered on the output side by the price of these outputs (net interest rate). The products we consider on the output side are current accounts, other resources (which includes term deposit accounts, emigrant accounts, investment funds, savings insurance, etc.), and credit. The bank under analysis distinguishes between two types of credit: directly by the bank and by associates. The former consists of all types of credit that the bank itself provides, while the latter consists of special types of credit that the bank provides through associate companies (like leasing or factoring credit).

An important output that is not included in our analysis is non-interest revenue. This is an increasingly important output since competitive pressures on bank profits have led bank branches to create other sources of revenues through commissions and fees (see e.g. Isik and Hassan, 2002). Unfortunately the bank was not able to supply this output and therefore we could not use it in our analysis.

Output prices provided by the bank are average net interest rates that were, therefore, assumed equal for all bank branches. The assumption of equal output prices amongst bank branches may be seen as a limitation of our approach but in fact rates do not vary much between branches. This is because rates charged to clients are set within centrally specified narrow ranges. Assuming branches have similar mix of clients the rates they earn from them will be on average similar.

\section{Some results of profit effiency and its components}

The profit efficiency approach was applied to a set of 57 bank branches all located in the north region of Portugal. The data used to illustrate the approach refers to the month of April 2001. Table 2 shows some statistics of our data in April, where monetary values are expressed in thousand Euros. As the models used are not standard we created our own codes in GAMS.

Maximum profit was calculated using model (2) rendering branch B16 as the sole profit efficient unit for all branches under analysis. This may be a result of similar output prices across bank branches, which does not allow for much discrimination in terms of profit maximising units (the only price that varied across branches was the price of staff-average salaries). In order to check for the sensitivity of the maximum profit solution to changes in prices, we simulated price differences by adding to the original output prices of each branch a random number varying between 0 and 0.02 . Note that our prices are net interest rates that range from 0.0059 for credit by the bank to 0.0419 for current accounts. ${ }^{6}$ The results from our simulated prices are very similar to those with constant prices. With simulated prices branches B17 and B16 appear most of the times as the profit maximising units. In some attempts only B17 was identified and in other attempts only B16 was identified as profit maximising. This fact seems to suggest that our results are not very sensitive to the fact that equal prices across branches were used for outputs.

\footnotetext{
${ }^{6}$ Credit has lower interest rate than current accounts because the bank considers a risk factor included in the interest rate of credit.
} 
Table 2

Descriptive statistics of our data for April

\begin{tabular}{llllrrrr}
\hline & Staff & Supplycost & Curracc. & Othress. & \multicolumn{1}{c}{ Credb. } & Credass. & Staffcost \\
\hline Average & 5.18 & 18.57 & 4001.25 & 11190.63 & 9313.16 & 848.05 & 14.16 \\
St. dev. & 1.17 & 4.80 & 1711.72 & 5891.55 & 4022.52 & 588.86 & 3.36 \\
Max & 7.00 & 31.00 & 7361.82 & 29726.24 & 21512.11 & 2806.21 & 20.14 \\
Min & 3.00 & 7.93 & 402.90 & 1022.09 & 1609.16 & 61.74 & 7.02 \\
\hline
\end{tabular}

Technical profit efficient targets were calculated through the CT procedure detailed earlier. Model (3) was solved for each facet identified by QHull and the minimum value across facets was chosen as the solution providing the CTs for the unit being assessed.

In order to analyse some of the information resulting from assessments of profit efficiency let us look with more detail to branch B8 in Table 3. In this table we show the target levels that render this branch, technically efficient and profit maximising.

The GDF overall profit efficiency of branch B8 is $37.68 \%$. This value is obtained by applying (1) to measure the distance between the observed point and the maximum profit target. The GDF distance between the CT and branch B8 renders a GDF score of $81.83 \%$, which is its technical profit efficiency score. Allocative profit efficiency can be simply calculated as the ratio between overall profit efficiency and technical profit efficiency, which equals $\frac{37.68 \%}{81.83 \%}=46.042 \%$. The decomposition of this allocative measure of efficiency into a mix and scale effect through model (4), results in a value of $\alpha$ of 2.496011, and a value of $\gamma$ of 3.662867. This gives a scale effect of $0.6814(2.496011 / 3.662867)$ and a mix effect of 0.6757 . The mix effect reflects the distance between the scale adjusted point (shown in Table 3) and the maximum profit point.

Note that branch $\mathrm{B} 8$ has a very low overall profit efficiency, which is mostly due to a very low allocative efficiency $(46.042 \%)$ rather than to technical efficiency $(81.83 \%)$. In addition, the low allocative efficiency is a result of a low scale effect that shows an IRS movement from the technical efficient point to the maximum profit point (on average outputs increased more than proportionally with inputs), and a low mix effect that shows still great changes in mix from the scale adjusted point to the maximum profit point.

Detailed results for all bank branches under analysis are shown in Table 4. In this table we show the GDF efficiency score for overall profit efficiency and for its technical and allocative components, as well as the scale and mix effects of allocative efficiency. In addition, the level of profit at the observed, the technically efficient, and the maximum profit point for the input/output prices of each bank branch are also shown in this table.

As mentioned before, overall profit efficiency and allocative profit efficiency can be higher than 1 . This situation happened only for one bank branch in our sample (B28) as can be seen in Table 4. Branch B28 is technically efficient, and no scale effects can be identified in moving from the observed level of inputs and outputs of B28 to those of the maximum profit branch (B16). This means that all overall profit inefficiency of B28 is explained by allocative inefficiency, which reflects very dissimilar product mixes between these two branches. In order to better understand why allocative efficiency is in excess of one for B28, consider an

Table 3

Targets of branch B8

\begin{tabular}{llllrrrr}
\hline & Staff & Supplycost & Curracc. & \multicolumn{1}{c}{ Othress. } & \multicolumn{1}{c}{ Credb. } & Credass. & GDF \\
\hline B8-Obs. & 4.0000 & 13.2181 & 2009.8513 & 4751.0899 & 4986.2581 & 248.7056 \\
CT & 3.3481 & 10.7413 & 2009.8513 & 4902.2491 & 4986.2581 & 248.7056 & $81.83 \%$ \\
Max. profit tgt. & 7.0000 & 26.8104 & 7361.8180 & 20266.4129 & 21512.1108 & 2306.9752 & $37.68 \%$ \\
Scale adj. & 8.357 & 26.8104 & 7361.8180 & 17956.2865 & 18264.0000 & 910.9760 & \\
\hline
\end{tabular}




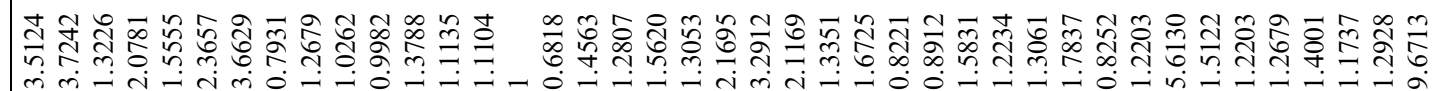

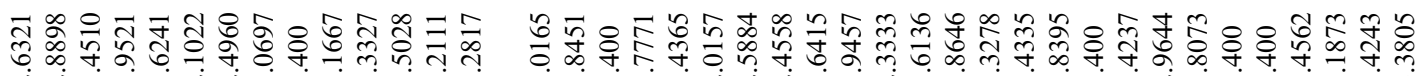

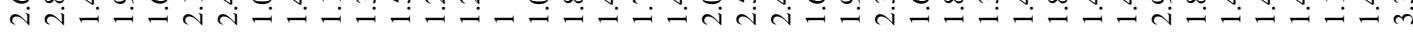

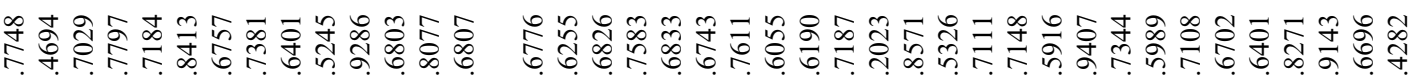

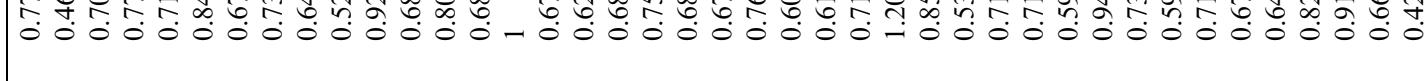

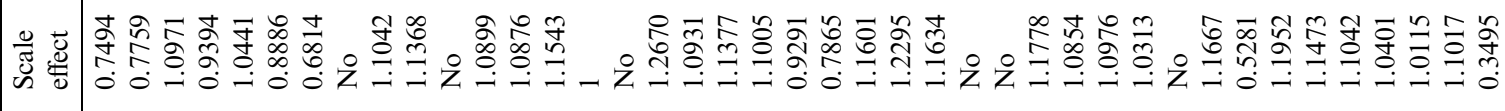

(2)

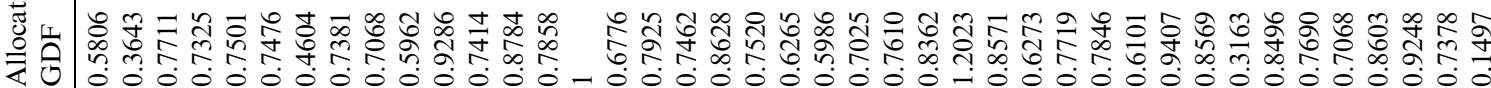
$00000000000000-00000000001000000000000000$

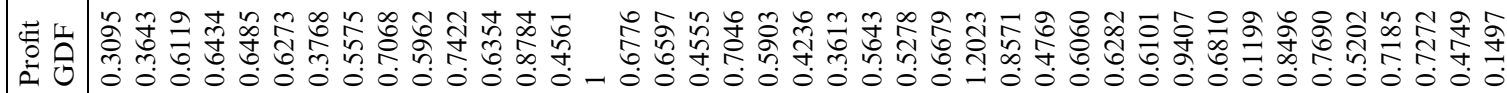

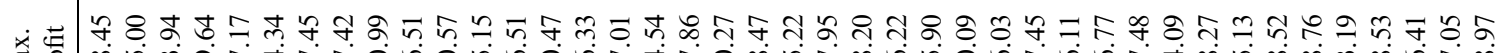

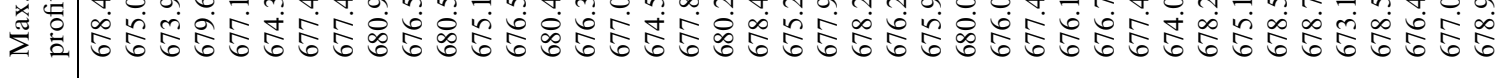
㺃

青

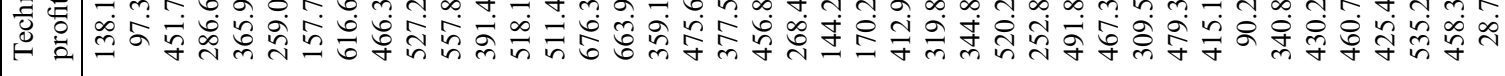

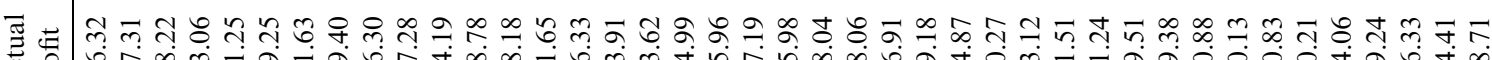

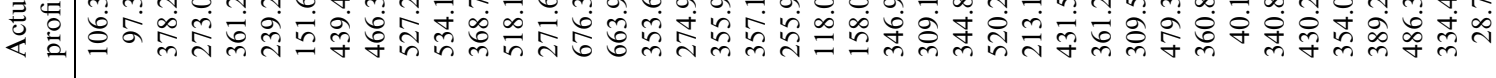

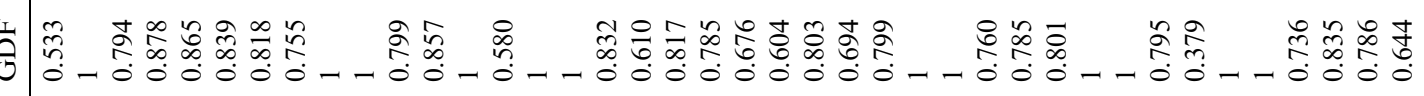




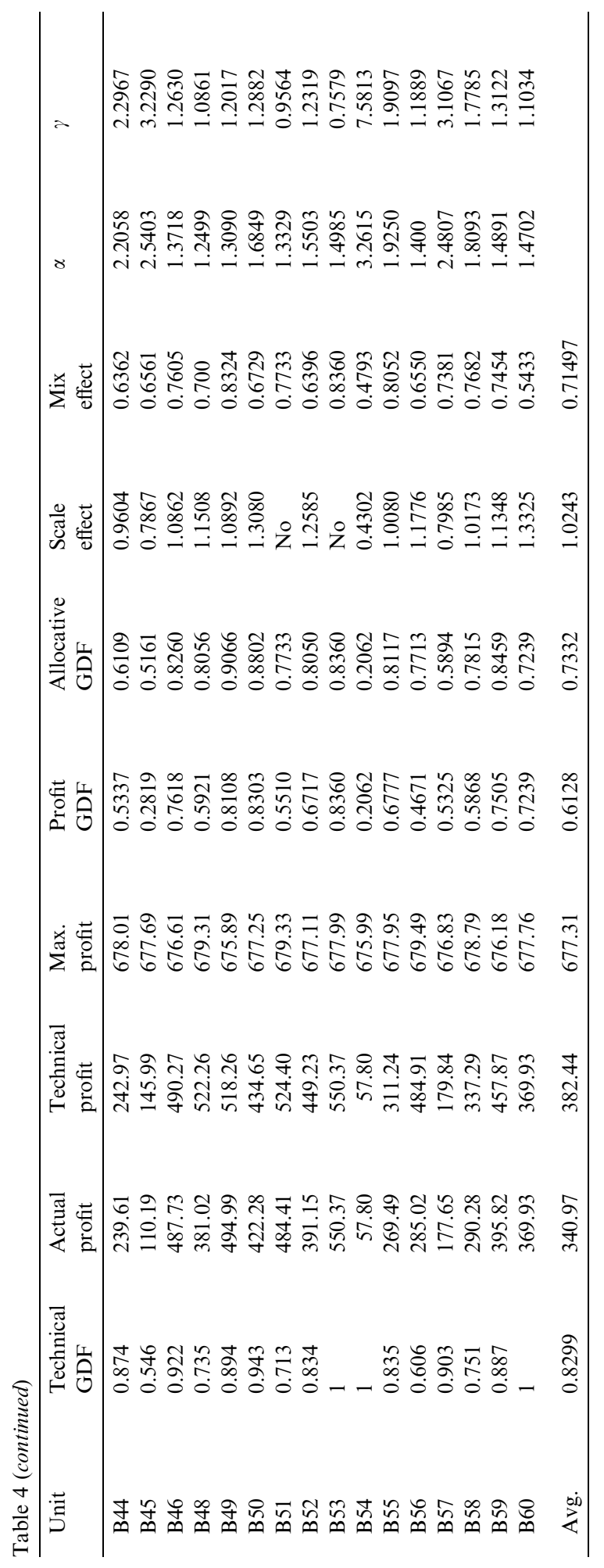


aggregate measure of productivity $\left[\left(\Pi_{r} \frac{y_{r}}{\text { staff }} \times \Pi_{r} \frac{y_{r}}{\text { supplycost }}\right)^{\frac{1}{s \times m}}\right]$ to be calculated at the observed and maximum profit points. Productivity of B28 at the observed point (which coincides with the technical efficient point) is 814.076 and productivity at the maximum profit point is 677.1288 . This means that a movement from the observed/technical efficient point to the maximum profit point implies a decrease in aggregate productivity, and as such this movement is only advisable under a profit perspective. In fact the aggregate productivity at the observed/technical efficient point is $\frac{814.076}{677.1288}=1.202$ times higher than the productivity at the maximum profit point. For the case of branch B28, movements from the technical efficient point to the maximum profit point involve trade-offs of such an order that may not be in fact advisable or even possible.

Results in Table 4 show an average profit inefficiency of $39.43 \%$ (measured as the absolute deviation of the GDF profit efficiency from 1), this value being mostly explained by allocative inefficiency (average allocative inefficiency is $27.39 \%$ ) and less by technical inefficiency (average technical inefficiency is $17.01 \%$ ). This means that though units are relatively close to the technical efficient frontier, this frontier is far away from the maximum profit plane resulting in high allocative inefficiencies. The average scale effect of the allocative efficiency is 1.0243 , which indicates that on average inputs increased more than outputs in movements from technical efficient projections to the maximum profit point. This fact indicates average DRS in such movements, but these are not very marked as the scale effect value is very close to 1 . The mix effect (averaging 71.5\%), on the other hand, seems to be the main reason for the low allocative efficiency.

Note that depending on the way technical efficient targets are calculated the technical efficiency and allocative efficiency components will differ. Under the CT procedure used in this paper we are asking a lower effort of production units to move to the production frontier than under, for example, the additive model. Thus for a given level of profit efficiency, CT-based technically efficient targets result in lower allocative efficiencies than when efficient targets are calculated through the additive model. Every path towards the production frontier can be used within our framework, and each one is valid for calculating technical efficiency. Nevertheless, one needs to be aware of the implications the path chosen has on the resulting measures of technical and allocative efficiency.

The above analysis considers only changes in inputs and outputs measured through the GDF. For the bank, however, it is important to translate the GDF results into profit gains arising from movements towards technical efficient or maximum profit targets. Profit ratios or differences provide interesting insights into this analysis. Let us consider for example branch B17. Its actual profit (which is also technical efficient profit) is about 663.9 thousand Euros, and its maximum profit is very close to it: about 677 thousand Euros. This seems to suggest that the profit efficiency of this branch is very high. However, analysing the overall profit GDF measure we see that its value is small $(67.76 \%)$. This means that, in order to move from its actual position to the maximum profit point, branch B17 needs to change considerably its mix of inputs and/or outputs (in fact all profit inefficiency in this case is explained by mix effects). Such a change in the mix of operations might be questioned by units whose profit is already close to maximum profit.

The overall profit gain obtained by moving from observed points to maximum profit points is the sum of the profit gained by moving from observed points to technical efficient points and the profit gained by moving from technical efficient points to maximum profit points. Overall profit gains (on average 336.34 thousand Euros) are in our case mainly attributed to allocative movements (average gain of 294.867 thousand Euros) rather than technical movements (average gain of 41.5 thousand Euros). While the increase in profits obtained from the elimination of technical inefficiency might be possible to achieve in the short run, those accruing from the elimination of allocative inefficiency might be unrealistic in the short run as they imply a considerable change in inputs and outputs of the production units (as reflected in a large value of GDF allocative inefficiency). This means that more realistic profit maximising targets should be imposed, so that bank branches can in fact strive to achieve maximum profit targets rather than just technical efficient targets. This issue is the subject of the next section. 


\section{Constrained maximum profit}

The maximum profit model presented previously assumes that all factors are variable. This is a usual assumption in long run profit maximisation, but in the short run some factors may not be possible to change and should therefore be considered fixed (see e.g. Färe et al., 1990). In our case, bank branches have a limited scope to change production factors in the short run. This means that there are no fixed factors, but bank branches cannot increase or decrease production factors by more than certain amounts. The idea of maximum profit under constraints was explored in Färe and Grosskopf (1994) (see also Färe et al., 1994, Chapter 10) where the authors put forward cost, revenue, and profit models with additional constraints. These models are called 'indirect' cost and revenue models. The use of constrained maximum profit was also put forward by Cooper et al. (2000). These authors used the additive model to decompose overall profit gains into those attributable to technical and allocative sources. The models used had additional bounds on the slacks "so that the resulting projections do not go far from the observed values and remain in managerially and technically allowable ranges" (Cooper et al., 2000, p. 225).

In the present case we impose some bounds on target inputs and outputs, so that these targets are attainable in the short run. Note that imposing bounds on each input (or output) is related to imposing a budget constraint (or revenue constraint), where each of the terms forming the total cost (or total revenue) are considered individually. For example, a constraint imposing that target inputs should be lower than a given percentage of observed inputs $\left(x_{i} \leqslant \alpha x_{i o}\right)$ is equivalent to a constraint imposing target costs to be lower than a given percentage of observed costs $\left(w_{i} x_{i} \leqslant \alpha w_{i} x_{i o}\right.$ which is equivalent to $\left.C_{i} \leqslant \alpha C_{i o}\right)$.

The input and output constraints considered in this application are that input and output levels should not vary by more than $30 \%$ above or below their observed level. These constraints, assuming the form shown in (8), can be directly incorporated into the maximum profit model (2).

$$
0.7 x_{i o} \leqslant x_{i} \leqslant 1.3 x_{i o} ; \quad 0.7 y_{r o} \leqslant y_{r} \leqslant 1.3 y_{r o} .
$$

As far as the measurement of technical efficiency is concerned, the imposition of constraints (8) may imply projections, which are not Pareto-efficient. This means that the CT model (3) cannot be used together with constraints on target input and output levels, as that model forces projections to be on Pareto-efficient facets. As an alternative, to measure technical efficiency in the presence of input and output constraints, we use model (9).

$$
\begin{aligned}
\mathrm{EFF}_{o}=\min _{\lambda_{j}, \theta, \beta}\left\{\theta / \beta \mid \sum_{j=1}^{n} \lambda_{j} y_{r j} \geqslant \beta y_{r o}, \sum_{j=1}^{n} \lambda_{j} x_{i j} \leqslant \theta x_{i o}, \sum_{j=1}^{n} \lambda_{j}=1,\right. \\
\left.\sum_{j=1}^{n} \lambda_{j} y_{r j} \leqslant 1.3 y_{r o}, \sum_{j=1}^{n} \lambda_{j} x_{i j} \geqslant 0.7 x_{i o}, \lambda_{j} \geqslant 0,0 \leqslant \theta \leqslant 1, \beta \geqslant 1\right\} .
\end{aligned}
$$

The constrained model (9) uses an equiproportional factor for contracting inputs and a different equiproportional factor for expanding outputs. The objective function of (9) is therefore a special case of the GDF measure where all inputs and outputs are assumed to change in the same proportion. The above model can result in some non-zero slacks, which can be accounted for by calculating the GDF a posteriori using the targets $\left(\sum_{j=1}^{n} \lambda_{j} x_{i j}, \sum_{j=1}^{n} \lambda_{j} y_{r j}\right)$ resulting from (9). Note that, as we are measuring technical efficiency, we maintain in $(9)$ the original assumption that inputs cannot be expanded $(\theta \leqslant 1)$ and outputs cannot be contracted $(\beta \geqslant 1)$ towards the technical efficient frontier. This means that only upper bounds are required on output changes and only lower bounds are required on input changes. Note that the constraints restricting target inputs and outputs result in $\beta$ values that are no larger than 1.3 and $\theta$ values that are no lower than 0.7 . 
Some results from constrained maximum profit models

Using the above constrained models we have re-done the calculations for our sample of bank branches. In Table 5 we consider again some detailed results for branch B8.

The technical efficient targets and maximum profit targets of branch B8 are much closer to observed values than before, and also much closer between each other. After reaching the technological constrained frontier branch B8 only needs to change its inputs to become a profit maximising unit. As a result, allocative efficiency is now much higher than before $(97.24 \%(=0.6797 / 0.69897)$ as opposed to a value of $46.04 \%$ for the unconstrained long run profit model).

As far as the maximum profit model is concerned all the branches have at least one of the ratios between maximum profit target outputs and observed outputs equal to the upper bound of 1.3. This means that this upper bound is the main impediment to units increasing their profits. The bounds on inputs, in contrast, do not have a big impact on both the maximum profit and the technical efficiency models as most of these bounds are not binding.

The detailed results for all units are presented in Table 6.

These results show an average profit inefficiency that is now lower than before $(20.35 \%$ compared to $39.43 \%$ in the unconstrained long run model). The main difference between this model and the long run model concerns the factors that most explain overall profit inefficiency. In the short run constrained model most of the profit inefficiency is explained by technical inefficiency, which is on average $15.36 \%$. Allocative effects are very small as confirmed by an average allocative inefficiency of $8.3 \%$.

Several branches in Table 6 have overall and allocative profit efficiency values greater than 1 . The interpretation here is the same as before, i.e. efficiency values higher than 1 indicate geometric average changes in inputs that are higher than geometric average changes in outputs, meaning that between the two points being considered, though profit increases, aggregate productivity decreases and therefore these movements might not be advisable.

In terms of overall profit gains these amount to 91.283 thousand Euros, of which 40.73 thousand Euros are obtained by technical constrained movements and the remaining 50.553 thousand Euros by allocative movements. Though allocative inefficiency is now much lower than before, allocative movements still generate higher profit gains than technical efficiency movements. This is an expected result because technical movements do not take into account factor prices. The above allocative profit gains and allocative efficiency values, therefore, tell us that very small input and output quantity movements are required to considerably increase profit.

We did not show in Table 6 the decomposition of allocative efficiency into its mix and scale effect because in the constrained model technical efficient projections (as resulting from model (9)) do not necessarily lie on the Pareto-efficient frontier. This means that a movement from the technical projection to the maximum profit point is not necessarily a movement along the production frontier and therefore the scale concept loses its meaning.

Table 5

Constrained targets for branch B8

\begin{tabular}{llllllll}
\hline & Staff & Supplycost & Curracc. & Othress. & Credb. & Credass. & GDF \\
\hline B8-Obs. & 4.0000 & 13.2181 & 2009.8513 & 4751.0899 & 4986.2581 & 248.7056 \\
Technical tgt. & 3.5989 & 12.1302 & 2612.8067 & 6176.4169 & 6482.1355 & 323.3173 & $69.897 \%$ \\
Max profit tgt. & 3.3663 & 12.2623 & 2612.8067 & 6176.4169 & 6482.1355 & 323.3173 & $67.97 \%$ \\
Scale adj. & 3.6381 & 12.2623 & 2612.8067 & 6176.4169 & 6482.1355 & 323.3173 & \\
\hline
\end{tabular}


Table 6

Short run results for all branches under analysis

\begin{tabular}{|c|c|c|c|c|c|c|}
\hline Unit & $\begin{array}{l}\text { Technical } \\
\text { GDF }\end{array}$ & $\begin{array}{l}\text { Actual } \\
\text { profit }\end{array}$ & $\begin{array}{l}\text { Technical } \\
\text { profit }\end{array}$ & $\begin{array}{l}\text { Max. } \\
\text { profit }\end{array}$ & $\begin{array}{l}\text { Profit } \\
\text { GDF }\end{array}$ & $\begin{array}{l}\text { Allocative } \\
\text { GDF }\end{array}$ \\
\hline $\mathrm{B} 1$ & 0.9275 & 106.3184 & 108.42915 & 143.0929 & 0.7989 & 0.8613 \\
\hline $\mathrm{B} 2$ & 1 & 97.3051 & 97.30510 & 129.7447 & 0.8648 & 0.8648 \\
\hline B3 & 0.7842 & 378.2209 & 480.67260 & 504.6245 & 0.7481 & 0.9540 \\
\hline B4 & 0.8386 & 273.0558 & 310.07878 & 361.0262 & 0.8045 & 0.9594 \\
\hline B5 & 0.8015 & 361.2471 & 453.35105 & 478.1158 & 0.8052 & 1.0046 \\
\hline B7 & 0.8676 & 239.2481 & 270.02312 & 318.8085 & 0.7728 & 0.8906 \\
\hline B8 & 0.6990 & 151.6340 & 206.52801 & 207.0281 & 0.6797 & 0.9724 \\
\hline B9 & 0.7049 & 439.3986 & 454.57460 & 586.3657 & 0.7392 & 1.0487 \\
\hline $\mathrm{B} 10$ & 1 & 466.3009 & 466.30088 & 592.5124 & 1.0111 & 1.0111 \\
\hline B11 & 1 & 527.2822 & 527.28215 & 609.4086 & 0.8253 & 0.8253 \\
\hline $\mathrm{B} 12$ & 0.8015 & 534.1887 & 557.54341 & 624.7948 & 0.9995 & 1.2471 \\
\hline B13 & 0.8115 & 368.7802 & 452.05041 & 486.7443 & 0.8390 & 1.0339 \\
\hline B14 & 1 & 518.1845 & 518.18448 & 622.2477 & 0.9719 & 0.9719 \\
\hline B15 & 0.5481 & 271.6529 & 377.27260 & 377.9110 & 0.5385 & 0.9824 \\
\hline B16 & 1 & 676.3324 & 676.33237 & 676.3324 & 1 & 1 \\
\hline B17 & 1 & 663.9061 & 663.90613 & 665.0342 & 0.9331 & 0.9331 \\
\hline $\mathrm{B} 18$ & 0.7514 & 353.6209 & 470.38098 & 470.5757 & 0.7449 & 0.9914 \\
\hline B19 & 0.7075 & 274.9940 & 370.42178 & 373.8030 & 0.6189 & 0.8747 \\
\hline B20 & 0.8565 & 355.9633 & 406.98850 & 468.6585 & 0.8195 & 0.9568 \\
\hline B21 & 0.7703 & 357.1945 & 448.00057 & 474.4561 & 0.7933 & 1.0299 \\
\hline B22 & 0.6170 & 255.9806 & 351.51816 & 352.5352 & 0.5928 & 0.9608 \\
\hline B23 & 0.9226 & 118.0366 & 120.72828 & 158.0336 & 0.8132 & 0.8814 \\
\hline B25 & 0.8700 & 158.0580 & 177.73471 & 212.3759 & 0.7516 & 0.8638 \\
\hline B26 & 0.7925 & 346.9126 & 415.33158 & 463.1748 & 0.7122 & 0.8986 \\
\hline B27 & 0.9201 & 309.1799 & 319.81775 & 408.2276 & 0.8152 & 0.8860 \\
\hline B28 & 1 & 344.8654 & 344.86545 & 422.9926 & 1.0534 & 1.0534 \\
\hline B29 & 1 & 520.2660 & 520.26602 & 582.6710 & 1.1787 & 1.1787 \\
\hline B30 & 0.6777 & 213.1180 & 290.43979 & 291.7372 & 0.6465 & 0.9540 \\
\hline B31 & 0.8059 & 431.5106 & 443.38613 & 569.5499 & 0.8441 & 1.0475 \\
\hline B32 & 0.8332 & 361.2376 & 428.51334 & 478.6704 & 0.7938 & 0.9527 \\
\hline B33 & 1 & 309.5077 & 309.50767 & 404.8235 & 0.9202 & 0.9202 \\
\hline B34 & 1 & 479.3802 & 479.38018 & 547.4322 & 1.0965 & 1.0965 \\
\hline B35 & 0.7291 & 360.8813 & 445.96459 & 481.8726 & 0.7093 & 0.9729 \\
\hline B36 & 0.8174 & 40.1334 & 53.45020 & 71.2375 & 0.5385 & 0.6588 \\
\hline B37 & 1 & 340.8308 & 340.83082 & 434.4143 & 0.9770 & 0.9770 \\
\hline B38 & 1 & 430.2069 & 430.20688 & 532.6527 & 1.0213 & 1.0213 \\
\hline B39 & 0.7035 & 354.0585 & 446.50716 & 474.5472 & 0.7338 & 1.0431 \\
\hline B40 & 0.7819 & 389.2439 & 481.38467 & 515.0694 & 0.7797 & 0.9972 \\
\hline B41 & 0.8445 & 486.3283 & 537.18397 & 602.3233 & 0.8610 & 1.0196 \\
\hline B42 & 0.6363 & 334.4092 & 382.01190 & 453.0310 & 0.6566 & 1.0319 \\
\hline B43 & 1 & 28.7062 & 28.70617 & 44.5861 & 0.6914 & 0.6914 \\
\hline B44 & 0.7863 & 239.6110 & 309.39457 & 319.9790 & 0.7248 & 0.9218 \\
\hline B45 & 0.7516 & 110.1883 & 125.46421 & 163.6107 & 0.5385 & 0.7164 \\
\hline B46 & 0.8773 & 487.7246 & 495.53449 & 629.0793 & 0.9446 & 1.0767 \\
\hline B48 & 0.6571 & 381.0220 & 459.40349 & 512.3651 & 0.6883 & 1.0474 \\
\hline B49 & 0.9166 & 494.9954 & 501.63115 & 647.3476 & 0.9186 & 1.0022 \\
\hline B50 & 0.9193 & 422.2828 & 445.04943 & 552.0547 & 0.9132 & 0.9934 \\
\hline B51 & 0.7657 & 484.4114 & 502.45214 & 597.7329 & 0.9040 & 1.1806 \\
\hline B52 & 0.7983 & 391.1534 & 492.43450 & 517.6991 & 0.7794 & 0.9764 \\
\hline B53 & 1 & 550.3749 & 550.37489 & 596.9433 & 1.2371 & 1.2371 \\
\hline B54 & 1 & 57.7969 & 57.79694 & 79.5834 & 0.7992 & 0.7992 \\
\hline B55 & 0.8264 & 269.4907 & 320.31263 & 357.5840 & 0.7954 & 0.9624 \\
\hline
\end{tabular}


Table 6 (continued)

\begin{tabular}{cllllll}
\hline Unit & $\begin{array}{l}\text { Technical } \\
\text { GDF }\end{array}$ & $\begin{array}{l}\text { Actual } \\
\text { profit }\end{array}$ & $\begin{array}{l}\text { Technical } \\
\text { profit }\end{array}$ & $\begin{array}{l}\text { Max. } \\
\text { profit }\end{array}$ & $\begin{array}{l}\text { Profit } \\
\text { GDF }\end{array}$ & $\begin{array}{l}\text { Allocative } \\
\text { GDF }\end{array}$ \\
\hline B56 & 0.7342 & 285.0171 & 381.60917 & 384.3587 & 0.6546 & 0.8916 \\
B57 & 0.7964 & 177.6528 & 221.71539 & 238.8651 & 0.7175 & 0.9010 \\
B58 & 0.7659 & 290.2821 & 386.49644 & 388.4463 & 0.6999 & 0.9139 \\
B59 & 0.8289 & 395.8153 & 474.08488 & 522.5592 & 0.8176 & 0.9864 \\
B60 & 1 & 369.9320 & 369.93196 & 457.0951 & 0.9695 & 0.9695 \\
Avg. & 0.8464 & 340.9725 & 381.70260 & 432.2552 & 0.8175 & 0.9666 \\
\hline
\end{tabular}

\section{Conclusion}

In this paper a newly developed procedure for calculating and decomposing profit efficiency is applied to a sample of Portuguese bank branches. This procedure is based on a measure of efficiency called GDF, which is a measure of the adjustments required in inputs and outputs to move from an observed point to a given target (on the technical frontier or on the profit frontier). The GDF approach was first applied to our data set assuming that all production factors were variable (long run models). Long run models may yield unrealistic targets to be attained in the short run. In addition, such models identify most of the profit inefficiency linked with allocative inefficiency. High allocative inefficiency implies that large input/output changes are required for a unit to move from a technical efficient projection to a maximum profit point. Such changes may be too big to be carried out in the short run. For this reason, short run constrained models were put forward so that more realistic targets could be proposed to bank branches. The constrained models result in smaller profit inefficiencies, which are mainly attributed to technical inefficiency rather than to allocative inefficiency. Small values of allocative inefficiency imply small input/output changes for a unit to move from a technical efficient projection to a maximum profit point. These small adjustments are guided by factor prices and therefore it is likely that profit gains are substancial. In our short run application, though technical inefficiency is higher than allocative inefficiency, profit gains resulting from eliminating allocative inefficiency are higher than those obtained from the elimination of technical inefficiency.

\section{Acknowledgements}

The authors acknowledge the financial support of the Portuguese Foundation for Science and Technology, and the European Social Fund. The contents of the paper are the responsibility of the authors.

\section{References}

Athanassopoulos, A.D., 1997. Service quality and operating efficiency synergies for management control in the provision of financial services: Evidence from Greek bank branches. European Journal of Operational Research 98, 300-313.

Banker, R.D., 1984. Estimating most productive scale size using data envelopment analysis. European Journal of Operational Research 17, 35-44.

Banker, R.D., Maindiratta, A., 1988. Nonparametric analysis of technical and allocative efficiencies in production. Econometrica 56 (6), 1315-1332.

Berger, A.N., Mester, L.J., 2000. Inside the black box; what explains differences in the efficiencies of financial institutions. In: Harker, P.T., Zenios, S.A. (Eds.), Performance of Financial Institutions; Efficiency, Innovation and Regulation. Cambridge University Press, Cambridge, UK, pp. 93-150.

Berger, A.N., Hancock, D., Humphrey, D.B., 1993. Bank efficiency derived from the profit function. Journal of Banking and Finance $17,314-347$. 
Berger, A.N., Leusner, J.H., Mingo, J.J., 1997. The efficiency of bank branches. Journal of Monetary Economics 40 (1), $141-162$.

Camanho, A.S., Dyson, R.G., 1999. Efficiency, size, benchmarks and targets for bank branches: An application of data envelopment analysis. Journal of the Operational Research Society 50 (9), 903-915.

Chambers, R.G., Chung, Y., Färe, R., 1996. Benefit and distance functions. Journal of Economic Theory 70, 407-419.

Chambers, R.G., Chung, Y., Färe, R., 1998. Profit, directional distance functions, and Nerlovian efficiency. Journal of Optimization Theory and Applications 98 (2), 351-364.

Chavas, J.-P., Cox, T.L., 1999. A generalized distance function and the analysis of production efficiency. Southern Economic Journal 66 (2), 294-348.

Cherchye, L., Kuosmanen, T., Post, T., 2001. Non-parametric production analysis under alternative price conditions. Center for Economic Studies, Katholieke Universiteit Leuven, Discussion Paper Series DPS 01.05.

Cooper, W.W., Seiford, L.M., Tone, K., 2000. Data Envelopment Analysis: A Comprehensive Text with Models, Applications, References and DEA-Solver Software. Kluwer Academic Publishers, Boston.

Doukas, J., Switzer, L.N., 1991. Economics of scale and scope in Canadian branch banking. Journal of International Financial Markets Institutions and Money 1, 61-84.

Färe, R., Grosskopf, S., 1994. Cost and Revenue Constrained Production. Springer-Verlag, New York.

Färe, R., Grosskopf, S., Lovell, C.A.K., 1985. The Measurement of Efficiency of Production. Kluwer-Nijhoff Publishing, Boston.

Färe, R., Grosskopf, S., Lee, H., 1990. A nonparametric approach to expenditure constrained profit maximization. American Journal of Agricultural Economics 12 (3), 574-581.

Färe, R., Grosskopf, S., Lovell, A.K., 1994. Production Frontiers. Cambridge University Press, Cambridge.

Hartman, T.E., Storbeck, J.E., Byrnes, P., 2001. Allocative efficiency in branch banking. European Journal of Operational Research 134, 232-242.

Humphrey, D.B., Pulley, L.B., 1997. Bank's responses to deregulation; profits, technology, and efficiency. Journal of Money, Credit, and Banking 29 (1), 73-93.

Isik, I., Hassan, M.K., 2002. Technical, scale, and allocative efficiencies of Turkish banking industry. Journal of Banking and Finance 26, 719-766.

Kuosmanen, T., 1999. Some remarks on scale efficiency and returns to scale in DEA. Helsinki School of Economics and Business Administration.

Lovell, C.A.K., Sickles, R.C., 1983. Testing efficiency hypothesis in joint production: A parametric approach. Review of Economics and Statistics 65 (1), 51-58.

Lozano Vivas, A., 1997. Profit efficiency for Spanish savings banks. European Journal of Operational Research 98, $381-394$.

Olesen, O.B., Petersen, N.C., 1996. Indicators of ill-conditioned data sets and model misspecification in Data Envelopment Analysis: An extended facet approach. Management Science 42 (2), 205-219.

Olesen, O.B., Petersen, N.C., 2002. Identification and use of efficient faces and facets in DEA. Journal of Productivity Analysis, Forthcoming.

Oral, M., Yolalan, R., 1990. An empirical study on measuring operating efficiency and profitability of bank branches. European Journal of Operational Research 46 (3), 282-294.

Pavlopoulos, P.G., Kouzelis, A.K., 1989. Cost behaviour in the banking industry: Evidence from a Greek commercial bank. Applied Economics 21, 285-293.

Portela, M.C.A.S., Thanassoulis, E., 2002. Profit efficiency in DEA. Aston Business School Research Paper RP 0206, ISBN 185449 502 X, University of Aston, Aston Triangle, Birmingham B4 7ET, UK.

Portela, M.C.A.S., Borges, P., Thanassoulis, E., 2003. Finding closest targets in non-oriented DEA models: The case of convex and non-convex technologies. Journal of Productivity Analysis 19 (2/3), 251-269.

Schaffnit, C., Rosen, D., Paradi, J.C., 1997. Best practice analysis of bank branches: An application of DEA in a large canadian bank. European Journal of Operational Research 98, 269-289.

Siems, T.F., Clark, J., 1997. Rethinking bank efficiency and regulation: How off-balance-sheet activities make a difference. Federal Reserve Bank of Dallas, Financial Industry Studies, December, 1-12. 